\section{Implementation of Secondary Prevention Methodologies in Ischemic Heart Disease}

\begin{abstract}
Ischemic heart disease (IHD) remains a major cause of mortality, morbidity, and disability in the U.S. and other developed countries and is an emerging epidemic in developing countries. As a result of therapeutic and preventive measures to control the IHD pandemic, mortality has declined steadily during the last several decades with consequent gains in life expectancy; however, this decrease in mortality started to plateau in the 1990's., ${ }^{1,2}$ Secondary prevention is identifying and treating people with established disease and those at very high risk of developing ischemic heart disease, which involves the treatment and rehabilitation of patients with known ischemic heart disease to prevent future cardiovascular events, including myocardial infarction, stroke, and heart failure.
\end{abstract}

${ }^{1}$ Nathan D. Wong, ${ }^{2,3}$ Duško B. Vulić, ${ }^{2,4}$ Marko Šobot

${ }^{1}$ Heart Disease Prevention Program, Division of Cardiology, Department of Medicine, University of California, Irvine, CA, USA, ${ }^{2}$ Department of Internal Medicine, University of Banja Luka , ${ }^{3}$ Center for Medical Research, Banja Luka, and ${ }^{4}$ Department of cardiovascular disease Clinical Center, Banja Luka, Republic of Srpska, Bosnia and Herzegovina

\section{Correspondence}

Duško Vulić, MD, PhD, F.E.S.C. Department of Internal Medicine, 78000 Banja Luka, Bosnia and Herzegovina email: dvulic@zdravljeisrce.com fax: $+387 / 51241-246$

\section{Key words}

ischemic heart disease, cardiovascular disease, risk factors, guidelines, prevention
The secondary prevention patient population includes those with established coronary and other atherosclerotic vascular disease, including peripheral arterial disease, atherosclerotic aortic disease and carotid artery disease. ${ }^{1}$ However, one might also consider expanding this to persons with other coronary heart disease risk equivalents, such as those with a $>20 \%$ 10-year calculated risk of IHD, diabetes, chronic kidney disease, or with significant subclinical coronary atherosclerosis (e.g., high levels of coronary artery calcification). Secondary prevention of coronary artery disease is effective in reducing morbidity and mortality, but deficiencies in implementation and prescription bias have been identified.

In evaluating the patients with preexisting coronary artery disease (CAD) for future risk of cardiovascular events, the value of the medical history, physical examination, 12-lead electrocardiogram, and selected laboratory tests cannot be overlooked. Originally, the Framingham Heart Study ${ }^{2}$ has assembled algorithms for determining the 2-year risk of IHD events, stroke, or cerebrovascular disease death in women (Table 1) and men (Table 2) with existing IHD. These tables may be useful for initial risk stratification, but they should be considered only approximate guides for assessing patient risk. Clinical presentation, including the type of chest pain present, as well as the presence of any associated co-morbidities (e.g., diabetes) also figure into the determination of prognosis. Other information about symptoms, coronary anatomy, left ventricular function, or results from exercise and/or nuclear stress imaging testing or newer biomarkers such as brain naturietic peptide (BNP) or troponin levels can provide important information for risk stratification.

\section{Risk Factor Modification and Secondary Preven- tion Guidelines}

Risk factor modification is the foundation of secondary prevention efforts in persons with IHD. ${ }^{1-3}$ This comprehensive approach involves lifestyle modification efforts including smoking cessation, diet, and physical activity, pharmacologic therapies to ensure control of blood pressure, lipids and glucose, and the use of cardioprotective drug therapies.

Over the past decade, guideline panels, including those from the American Heart Association (AHA) and American College of Cardiology (ACC) ${ }^{1}$ as well as European panels ${ }^{4}$, have developed a series of recommendations for therapy and clinical management of risk factors in persons with IHD (Tables 3, Tables 4, Tables 5). Evidence confirms that aggressive comprehensive risk factor management improves survival, reduces recurrent events and the need for interventional procedures, and improves the quality of life in these patients. 
Table 1. Risk of Coronary Artery Disease Event, Stroke, or Cerebrovascular Disease Death in Women with Existing Coronary Artery Disease

Points by HDL-C, mg/dL

\begin{tabular}{|c|c|c|c|c|c|c|c|c|c|c|c|c|c|}
\hline & & Total-C & & & & & & & & & & SBP & \\
\hline Age & Points & $\mathrm{Mg} / \mathrm{dl}$ & 25 & 30 & 35 & 40 & 45 & 50 & 60 & 70 & 80 & $\mathrm{mmHg}$ & Points \\
\hline 35 & o & 160 & 4 & 3 & 3 & 2 & 2 & 1 & 1 & 0 & O & 100 & o \\
\hline 40 & 1 & 170 & 4 & 3 & 3 & 2 & 2 & 2 & 1 & 1 & o & 110 & o \\
\hline 45 & 2 & 180 & 4 & 3 & 3 & 2 & 2 & 2 & 1 & 1 & o & 120 & 1 \\
\hline 50 & 3 & 190 & 4 & 4 & 3 & 3 & 2 & 2 & 1 & 1 & 1 & 130 & 1 \\
\hline 55 & 4 & 200 & 4 & 4 & 3 & 3 & 2 & 2 & 2 & 1 & 1 & 140 & 2 \\
\hline 60 & 5 & 210 & 4 & 4 & 3 & 3 & 3 & 2 & 2 & 1 & 1 & 150 & 2 \\
\hline 65 & 6 & 220 & 5 & 4 & 4 & 3 & 3 & 2 & 2 & 1 & 1 & 160 & 2 \\
\hline 70 & 7 & 230 & 5 & 4 & 4 & 3 & 3 & 3 & 2 & 2 & 1 & 170 & 3 \\
\hline \multirow[t]{4}{*}{75} & 7 & 240 & 5 & 4 & 4 & 3 & 3 & 3 & 2 & 2 & 1 & 180 & 3 \\
\hline & & 250 & 5 & 4 & 4 & 4 & 3 & 3 & 2 & 2 & 1 & 190 & 3 \\
\hline & & 260 & 5 & 5 & 4 & 4 & 3 & 3 & 2 & 2 & 1 & 200 & 3 \\
\hline & & 270 & 5 & 5 & 4 & 4 & 3 & 3 & 2 & 2 & 2 & 210 & 4 \\
\hline Other Points & & 280 & 5 & 5 & 4 & 4 & 3 & 3 & 3 & 2 & 2 & 220 & 4 \\
\hline Diabetes & 3 & 290 & 5 & 5 & 4 & 4 & 4 & 3 & 3 & 2 & 2 & 230 & 4 \\
\hline \multirow[t]{2}{*}{ Smoking } & 3 & 300 & 6 & 5 & 4 & 4 & 4 & 3 & 3 & 2 & 2 & 240 & 4 \\
\hline & & & & & & & & & & & & 250 & 4 \\
\hline
\end{tabular}

Average 2-year Risk in Women with CVD

\begin{tabular}{cccc}
\hline Total Points & 2-year Probability, percent & Age, years & Probability, percent \\
\hline 0 & 0 & $35-39$ & $<1$ \\
\hline 2 & 1 & $40-44$ & $<1$ \\
\hline 4 & 1 & $45-49$ & 4 \\
\hline 6 & 1 & $50-54$ & 8 \\
\hline 8 & 2 & $55-59$ & 12 \\
\hline 10 & 4 & $60-64$ & \\
\hline 12 & 6 & $65-69$ & \\
\hline 14 & 10 & $70-74$ & \\
\hline 16 & 15 & & \\
\hline 18 & 23 & & \\
\hline 20 & 35 & & \\
\hline 22 & 51 & & \\
\hline 24 & 68 & & \\
\hline 26 & 85 & & \\
\hline
\end{tabular}

Key: HDL-C, high-density-lipoprotein cholesterol; SBP, systolic blood pressure; CVD, cardiovascular disease. Source: Califf et al. ${ }^{2}$ with permission. 
Table 2.

Risk of Coronary Artery Disease Event, Stroke, or Cerebrovascular Disease Death in Men with Existing Coronary Artery Disease

Points by HDL-C, mg/dL

\begin{tabular}{lccccccccccccc}
\hline Age, years & Points & $\begin{array}{c}\text { Total-C, } \\
\mathrm{mg} / \mathrm{dL}\end{array}$ & 25 & 30 & 35 & 40 & 45 & 50 & 60 & 70 & 80 & $\begin{array}{c}\text { SBP } \\
(\mathrm{mmHg})\end{array}$ & Points \\
\hline 35 & $\mathrm{o}$ & 160 & 6 & 5 & 4 & 4 & 3 & 2 & 1 & 1 & o & 100 & 0 \\
\hline 40 & 1 & 170 & 6 & 5 & 5 & 4 & 3 & 3 & 2 & 1 & 0 & 110 & 1 \\
\hline 45 & 1 & 180 & 7 & 6 & 5 & 4 & 4 & 3 & 2 & 1 & 1 & 120 & 1 \\
\hline 50 & 2 & 190 & 7 & 6 & 5 & 4 & 4 & 3 & 2 & 2 & 1 & 130 & 2 \\
\hline 55 & 2 & 200 & 7 & 6 & 5 & 5 & 4 & 4 & 3 & 2 & 1 & 140 & 2 \\
\hline 60 & 3 & 210 & 7 & 6 & 6 & 5 & 4 & 4 & 3 & 2 & 1 & 150 & 3 \\
\hline 65 & 3 & 220 & 8 & 7 & 6 & 5 & 5 & 4 & 3 & 2 & 2 & 160 & 3 \\
\hline 70 & 4 & 230 & 8 & 7 & 6 & 5 & 5 & 4 & 3 & 3 & 2 & 170 & 4 \\
\hline 75 & 4 & 240 & 8 & 7 & 6 & 6 & 5 & 4 & 4 & 3 & 2 & 180 & 4 \\
\hline & 250 & 8 & 7 & 6 & 6 & 5 & 5 & 4 & 3 & 2 & 190 & 4 \\
\hline & 260 & 8 & 7 & 7 & 6 & 5 & 5 & 4 & 3 & 2 & 200 & 5 \\
\hline & & 270 & 9 & 8 & 7 & 6 & 6 & 5 & 4 & 3 & 3 & 210 & 5 \\
\hline Other Points & & 280 & 9 & 8 & 7 & 6 & 6 & 5 & 4 & 4 & 3 & 220 & 5 \\
\hline Diabetes & 1 & 290 & 9 & 8 & 7 & 7 & 6 & 5 & 4 & 4 & 3 & 230 & 6 \\
\hline & & 300 & 9 & 8 & 7 & 7 & 6 & 6 & 5 & 4 & 3 & 240 & 6 \\
\hline & & & & & & & & & & 250 & 6 \\
\hline
\end{tabular}

Average 2-year Risk in Men with CVD

\begin{tabular}{cccc}
\hline Total Points & 2-year Probability, percent & Age, years & Probability, percent \\
\hline 0 & 2 & $35-39$ & $<1$ \\
\hline 2 & 2 & $40-44$ & 10 \\
\hline 4 & 3 & $45-49$ & 11 \\
\hline 6 & 5 & $50-54$ & 12 \\
\hline 8 & 7 & $55-59$ & 12 \\
\hline 10 & 10 & $60-64$ & 14 \\
\hline 12 & 14 & $65-69$ & 14 \\
\hline 14 & 20 & $70-74$ & \\
\hline 16 & 28 & & \\
\hline 18 & 37 & & \\
\hline 20 & 49 & & \\
\hline 22 & 63 & & \\
\hline 24 & 77 & & \\
\hline
\end{tabular}

Key: HDL-C, high-density-lipoprotein cholesterol; SBP, systolic blood pressure; CVD, cardiovascular disease.

Source: Califf et al. ${ }^{2}$ with permission. 
Importantly, the revised AHA/ACC guidelines, based on compelling evidence from recent clinical trials and revised practice guidelines from the National Institutes of Health and the AHA/ACC allow for categorization according to classification of recommendation and level of evidence (A through C). ${ }^{1}$ The strongest guidelines are those classified as Class I, for which there is evidence or general agreement that the procedure or treatment is beneficial, useful and effective and/or where data are derived from multiple randomized clinical trials or meta-analyses (level of evidence A), whereas weakest are those classified as Class III (not useful/effective and possibly harmful) and/or with a level of evidence of $\mathrm{C}$ (only expert consensus, case studies, or standard of care). For instance the initiation of LDL-C lowering drug therapy when the LDL-C $>100 \mathrm{mg} / \mathrm{dl}$ is given a class Ia recommendation. The guidelines provides the level of recommendations and applicable classifications/ level of evidence for the key components of secondary prevention as outlined in Table 3, including their assessment, treatment goals, and recommended treatment approaches as recommended by the AHA/ACC.

\section{Status of Risk Factor Control and Recommended Treatments}

Previous studies have shown that cardiovascular risk factors among IHD patients are poorly controlled, ${ }^{4}$ with many exceeding target levels. ${ }^{5}$ Previous reports ${ }^{6}$ have focused on clinical or hospitalized samples, U.S. population data from free-living U.S. adults with IHD describing the adequacy of recommended treatments and risk factor control are limited. Recent reports from the U.S. National Health and Nutrition Examination Survey have shown barely a third of those with IHD to be at a recommended LDL-C $<100 \mathrm{mg} / \mathrm{dl}$ with only a sixth at recommended levels of all lipids, and less than half at recommended levels of blood pressure..$^{8-9}$ Since major risk factors account for $75 \%$ or more of the risk for developing a CVD event, ${ }^{10}$ the secondary prevention efforts should focus on achieving optimal risk factor control by all valid approaches. For instance, the daily use of a "polypill" containing an HMG CoA reductase inhibitor (simvastatin $40 \mathrm{mg}$ ), 3 blood pressurelowering medications (diuretic, beta blocker, angiotensin converting enzyme inhibitor at usual doses), folic acid (0.8 $\mathrm{mg}$ ), and aspirin (75 $\mathrm{mg}$ ) has been estimated to reduce recurrent cardiovascular events by $88 \% .^{11}$

\section{Implementation of Prevention Guidelines}

Lifestyle, risk factos, and therapeutic goals set by recommendations of Joint European Societies for coronary disease prevention in clinical practice are not realized by most patients throughout Europe..$^{12-18}$ Many national multicenter studies showed results similar to those in EUROASPIRE I (1995/96), EUROASPIRE II (1999/2000), and EUROASPIRE III (2006/2007) $\cdot^{3-19}$

The comparison between these EUROASPIRE surveys demonstrates a substantial gap between the standards set in the CVD prevention guidelines in clinical practice. These surveys, show that lifestyle trends in patients with IHD are growing cause for concern. ${ }^{14-11}$ Other surveys have also reported inadequate risk factors management and underuse of prophylactic drug therapies in patients with IHD in Spain (PREVESE I and II, in 1994 and 1998, ${ }^{20-21}$ France (PREVENIR,1998 and 1999, Usik 1998 and 2000),,22 Republic of Srpska/Bosnia and Herzegovina(ROSCOPS I,II,III) in 2000, $2003^{24}$ and 2007 , Croatia (TASPIC-CRO) in $1998^{23}$ and 2003, and Serbia in 2008/2009 25 . What is abundantly clear from these European surveys is that drug therapies are simply not sufficient and they have to be combined with the professional support to make lifestyle changes and also manage their risk factors more effectively. Simply giving a drug prescription is not enough. Patients need to understand the nature of their disease and how to manage it through achievin a healthy lifestyle and adhering to cardioprotective drug therapies over the long term. Most importany of all, adverse lifestyle trends in the general population calls to attention the urgent need for a societal strategy for CVD prevention. They illustrate how difficult it is for individual patients to change their behavior, despite the development of life-threatening disease, given that their unhealthy life-styles are shared by an ever-increasing proportion of the adult population. To help patients to quit smoking, adopt a healthy diet and increase physical activity requires sustained professional support. Yet only third of patients with coronary disease access cardiac rehabilitation programs in Europe. All patients with coronary disease as well as those at high risk of development CVD should be able to access preventive cardiology programs. ${ }^{11-15}$

The results of the management program of the cardiac hospitalizations for atherosclerosis (CHAMP) at UCLA carried out in two different groups of 256 and 302 patients also showed that a hospital-based strategy of RF increases the rates medication at discharge, from $6 \%$ for statins prior to implementation of the program in the years 1990-93 to $86 \%$ after running the program. One year after discharge $58 \%$ of patients reached LDL-cholesterol levels less than $100 \mathrm{mg} / \mathrm{dl}$ compared with only $6 \%$ of patients in the previous period. Many persons with IHD in the United States in 2005-2006 remain short of American Heart Association and American College of Cardiology recommended goals for BP, lipids and if diabetic, A1C. Vulic et al. recently reported treatment rates for recommended treatments (ACE/ARBs, beta-blockers and lipid-lowering medication) are higher than reports from previous investigations in clinical populations that have examined IHD patients. ${ }^{26}$ These studies demonstrate that under conventionally guided management, regardless of the health care delivery system, an unacceptably large number of IHD patients are left untreated by cardioprotective drugs. This low rate of patient adherence to therapy, undoubtedly, is a significant contributor to the large number of patients not being treated with evidence-based therapy on an outpatient basis. The underuse of cardioprotective drugs in patients with 
Table 3.

Components of Secondary Prevention

Cigarette smoking cessation

Blood pressure control

Lipid management to goal

Physical activity

Weight management to goal

Diabetes management to goal

Antiplatelet agents / anticoagulants

Renin angiotensin aldosterone system blockers

Beta blockers

Influenza vaccination

(Adapted from Smith et al. ${ }^{1}$ )

Table 4.

What Are the Objectives of Secondary CVD Prevention?

No smoking

Healthy food choices

Physical activity: 30 min of moderate activity a day

Body mass index (BMI) $<25 \mathrm{~kg} / \mathrm{m} 2$ and avoidance of central obesity

Blood pressure under 130/80 mmHg if feasible

Total cholesterol $<4.5 \mathrm{mmol} / \mathrm{l}(\sim 175 \mathrm{mg} / \mathrm{dl})$ with an option of $<4 \mathrm{mmol} / \mathrm{l}(\sim 155 \mathrm{mg} / \mathrm{dl})$ if feasible

LDL cholesterol $<2.5 \mathrm{mmol} / \mathrm{l}(\sim 100 \mathrm{mg} / \mathrm{dl})$ with an option of $<2 \mathrm{mmol} / \mathrm{l}(\sim 80 \mathrm{mg} / \mathrm{dl})$ if feasible

Fasting blood glucose $<6 \mathrm{mmol} / \mathrm{l}(\sim 110 \mathrm{mg} / \mathrm{dl})$ and glycosylated haemoglobin (HbA1c) $<6.5 \%$ if feasible

(Source: European Guidelines on CVD Prevention Fourth Joint European Societies Task Force on Cardiovascular Disease Prevention in Clinical Practice 2007; reproduced with permission from Graham et al. ${ }^{13}$ )
IHD represents a major clinical practice and public health mismanagement issue.

Adherence to lifestyle advice about diet, exercise and smoking cessation following acute coronary syndrome (ACS) has a substantial effect on lowering the risk of further events, according to a study of more than 18,000 patients. ${ }^{27}$ According to an accompanying editorial, this marked improvement in cardiovascular morbidity and mortality seen with lifestyle modification in the ACS population is "a novel and compelling finding". The editorial adds that such results "should raise a new level of focus on the timely initiation of behavioral modification after MI, similar to what is currently done with acute pharmacological intervention". It was striking in the study that at 30 days following ACS, 96.1\% of subjects had been prescribed antiplatelet drugs and $78.9 \%$ statins- while around one-third of smokers were still smoking, and adherence to neither diet nor exercise recommendations was reported by $28.5 \%$.

Multiple studies of the use of these recommended therapies in appropriate patients continue to show that many patients in whom therapies are indicated are not receiving them in actual clinical practice. The AHA , ACC and ESC urge that in all medical care settings where these patients are managed that programs to provide practitioners with useful reminder hints based on the guidelines, and continuously assess the success achieved in providing these therapies to the patients who can benefit from them be implemented. Data from a national samples of people with IHD show that a substantial majority were not optimally treated for BP, lipids, and HbA1c, but better in comparison with previous reports. ${ }^{24-26}$ Further research into identification of patient and provider factors, resulting in suboptimal treatment, is needed. Further education of patients and providers in the appropriate use of multiple or combination treatments to appropriately treat risk factors to goal is also needed. General practitioners are in a unique position to provide ongoing advice, support and counseling to such patients with established IHD, who require life-long risk factor control and treatment management. Table 6 lists ten important strategies for improving effectiveness of behavioral interventions.

\section{Conclusions}

Patients with established heart disease or CVD risk equivalents are at high risk for acute coronary events. Multiple randomized clinical trials have documented the valuable clinical benefits of aggressive risk factor modification for the prevention of recurrent events and mortality. Guidelines established by European, American, and other societies have described the assessment, goals, and management strategies for key areas of secondary prevention including smoking cessation, blood pressure control, lipid management, physical activity, weight management, diabetes management, antiplatelet therapy, renin-angiotensin system blockade, beta-blockade, and most recently, influenza 
vaccination. Aggressive and comprehensive management of all established risk factors should be initiated for most high-risk patients without delay. Close monitoring to ensure adherence to prescribed therapies and lifestyle modifications is crucial for the success of secondary prevention strategies. Further clinical trials will help establish the role of monitoring and treatment of newer emerging risk factors and biomarkers in secondary prevention efforts.

\section{Table 5.}

When to Prescribe Cardioprotective Drugs in Addition to Those Used to Treat Blood Pressure, Lipids and Diabetes

Aspirin or other platelet modifying drugs are recommended in all patients at high risk of occlusive arterial disease unless there are specific contraindications.

Beta-blockers after myocardial infarction and, in carefully titrated doses, in those with heart failure.

ACE inhibitors are indicated in all patients, unless there are contraindications, for the following reasons: (i) treatment of left ventricular dysfunction with or without over heart failure.

Anticoagulants in those at increased risk of thromboembolic events, particularly atrial fibrillation.

\section{Table 6.}

Ten Strategic Recommendations to Enhance the Effectiveness of Behavioral Counseling

Develop a therapeutic alliance

Counsel all patients

Ensure that patients understand the relationship between behavior and health

Help patients to assess the barriers to behavior change

Gain commitments from patients to behavior change

Involve patients in identifying and selecting the risk factors to change

Use a combination of strategies including reinforcement of patient's own capacity for change

Design a lifestyle modification plan

Monitor progress through follow-up contact

Involve other healthcare staff wherever possible

(Source: European Guidelines on CVD Prevention Fourth Joint European Societies Task Force on Cardiovascular Disease Prevention in Clinical Practice 2007. Reproduced with permission from Graham et al. ${ }^{13}$ )

\section{References}

1. Smith SC Jr, Allen J, Blair SN, Bonow RO et al.National Heart, Lung, and Blood Institute. AHA/ACC Guidelines for Secondary Prevention Patients with Coronary and other Atherosclerotic Vascular Disease: 2006 update, Circulation 2006;113:2363-72.

2. Califf RM, Armstrong PW, Carver JR, D’Agostino RB et al. $27^{\text {th }}$ Bethesda Conference: matching the intensity of risk factor management with the hazard for coronary disease events. Task Force 5. Stratification of patients into high, medium, and low risk subgroups for purposes of risk factor management. J Am Coll Cardiol 1996;27:1007-19.

3. Davigius ML, Lioyd-Jones DM, Pirzada A. Preventing cardiovascular disease in the $21^{\text {st }}$ century: Therapeutic and preventive implications of current evidence. Am J Cardiovasc Drugs 2006;6:87-101.

4. EUROSPIRE I and II Group. Clinical reality of coronary prevention guidelines: a comparation of EUROSPIRE I and II in nine countries. Lancet 2001;357:995-1001

5. Wong ND, Cupples LA, Ostfeld AM, Levy D et al. Risk factors for long-term coronary prognosis following initial myocardial infarction: the Framingham Study. Am J Epidemiol 1989;130: 469-80.

6. LaBresh KA, Fonarow GC, Smith SC Jr, Bonow RO et al. Get With The Guidelines Steering Committee. Improved treatment of hospitalized coronary artery disease patients with the get with the guidelines program. Crit Pathw Cardiol 2007;6:98-105.

7. Fonorow GC, French WJ, Parsons LS, Sun $\mathrm{H}$ et al. Use of lipid-lowering medications at discharge in patients with acute myocardial infarction: Data from the National Registry of Myocardial Infarction 3. Circulation 2001;103:38-44.

8. Ghandehari H, Kamal-Bahl S, Wong ND. Prevalence and extent of dyslipidemia and recommended lipid levels in US adults with and without cardiovascular comorbidities: the National Health and Nutrition Examination Survey 2003-2004. Am Heart J 2008;156:112-9.

9. Wong ND, Lopez VA, L'Italien $\mathrm{G}$, Chen $\mathrm{R}$ et al. Inadequate control of hypertension in US adults with cardiovascular disease comorbidities in 2003-2004. Arch Intern Med 2007;167: 2431-6.

10. Magnus $P$, Beaglehole R. The real contribution of the major risk factors to the coronary epidemics; time to end the "only-50\%" myth. Arch Intern Med 2001;161:2657-60.

11. Wald NJ, Law MR. A strategy to reduce cardiovascular disease by more than $80 \%$ [published erratum in: BMJ;327:586]. BMJ 2003;326:1419.

12. De Backer G, Ambrosioni E, Borch-Johnsen K, Brotons C et al. European guidelines on cardiovascular disease prevention in clinical practice: third joint task force of European and other societies on cardiovascular disease prevention in clinical practice. Eur J Cardiovasc Prev Rehabil 2003; 2(Suppl. 1):2-63.

13. Graham I, Atar D, Borch-Johnsen K, Boysen G et al. European Guidelines on Cardiovascular Disease Prevention in clinical practice: full text. Fourth Joint Task Force of the European Society of Cardiology and other Societies on Cardiovascular Disease prevention in clinical practice. Eur J Cardiovasc Prev Rehabil 2007; 14(Suppl. 2):S1-S113.

14. Kotseva K, Wood D, De Backer G, De Bacquer D et al. EUROASPIRE III: A survey on the lifestyle, risk factors and use 
of cardioprotective drug therapies in coronary patients from twenty-two European countries. Eur J Cardiovasc Prev Rehabil 2009;16:121-37.

15. Kotseva K, Wood D, De Backer G, De Bacquer D et al. Cardiovascular prevention guidelines in daily practice: a comparison of EUROASPIRE I, II, III surveys in eight European countries. Lancet 2009;373: 929-40.

16. Brekke M, Gjelsvik B. Secondary cardiovascular risk prevention - we can do better. Lancet 2009; 373:873-974.

17. Brook RD, Greenland P. Secondary prevention. In: Wong ND, Black HR, Gardin JM, ed. Textbook of Preventive Cardiology: A Practical Approach. USA: McGraw-Hill Companies 2005. pp. 583-99.

18. Fonarow GC. Implementation of preventive cardiology guidelines. In: Wong ND, Black HR, Gardin JM, ed. Textbook of Preventive Cardiology: A Practical Approach. USA: McGraw-Hill Companies 2005. pp. 599-614.

19. Wood AD, Kotseva K. Should cardiovascular disease prevention be undertaken by doctors or policymakers and politicians? Dialogues in Cardiovasc Med 2009;14:83-98.

20. De Velasco JA, Cosin J, Lopez-Sendon JL De Teresa et al. Secondary prevention of myocardial infarction in Spain. The PREVESE study. Rev Esp Cardiol.1997;50:406-15.

21. De Velasco JA, Cosin J, Lopez-Sendon JL, De Teresa E et al G. New data on secondary prevention of myocardial infarction in Spain. Results of PREVESE II study. Rev Esp Cardiol.2002;55: 801-9.
22. Danchin N, Hanania G, Grenter O, Aur L et al. Trends in discharge prescriptions for patients hospitalized for acute coronary syndrome in France from 1995 to 2000.Data from the Usik 1995,PREVENIR 1,2 and Usic 2000 surveys. Ann Cardiol Angeiol. 2003;52:1-6.

23. Reiner Z, Mihatov S, Milicic D, Bergovec et al. Treatment and secondary prevention of ischaemic coronary events in Croatia(TASPIC-CRO study). Eur J Cardiovasc Prev Rehabil.20o6;13:646-54.

24. Vulic D, Loncar S, Krneta M, Skrbic R et al. Risk factors control and adherence to treatment in Republic of Srpska-Bosnia and Herzegovina in patients with coronary heart disease 20052006. Arch Medical Sci 2010; 6:270-75.

25. Tasic I, Aleksic E, Lazarevic G, Djordjevic D et al. The prognostic factors in patients with survived myocardial infarction. Cenl Europ J Med 2010 (in press)

26. Vulic D, Lee TB, Lopez AV, Wong DN. Extent of control of cardiovascular risk factors and compliance to recommended therapies in U.S. multiethnic adults with coronary heart disease 2005-2006. Am J Cardiovasc Drugs 2010;10:109-14.

27. Chow CK, Jolly S, Rao-Melacini P.Fox KA et al. Association of diet, exercise, and smoking modification with risk of early cardiovascular events after acute coronary syndromes. Circulation 2010;121:750-58. 